\title{
A case of subaortic stenosis
}

\author{
Guillaume Abehsira, MD, ${ }^{\mathrm{a}}$ Thierry Waldmann, $\mathrm{MD},{ }^{\mathrm{b}}$ and Philippe Estagnasié, $\mathrm{MD}^{\mathrm{a}}$
}

A 56-year-old woman who reported dyspnea and was in New York Heart Association functional class III was admitted initially to undergo aortic valve replacement for severe aortic stenosis. Echocardiography performed 2 months previously had found a severe aortic stenosis with valve area less than $1 \mathrm{~cm}^{2}$, mean gradient $40 \mathrm{~mm} \mathrm{Hg}$, and maximum jet velocity $4 \mathrm{~m} / \mathrm{s}$, associated with low aortic regurgitation. The preoperative echocardiography showed no major aortic

From the Intensive Care Unit of Cardiovascular Surgery, ${ }^{\mathrm{a}}$ Clinique Ambroise Paré, Neuilly-sur-Seine, France; and Cardiac Surgery, ${ }^{\mathrm{b}}$ Clinique Ambroise Paré, Neuilly-sur-Seine, France.

Disclosures: Authors have nothing to disclose with regard to commercial support.

Received for publication June 9, 2013; revisions received June 9, 2013; accepted for publication June 12, 2013; available ahead of print July 15, 2013.

Address for reprints: Guillaume Abehsira, MD, Clinique Ambroise Paré, 27 Boulevard Victor Hugo, 92200, Neuilly-sur-Seine, France (E-mail: guillaume. abehsira@ hotmail.fr).

J Thorac Cardiovasc Surg 2014;147:522-3

$0022-5223 / \$ 36.00$

Copyright (c) 2014 by The American Association for Thoracic Surgery

http://dx.doi.org/10.1016/j.jtcvs.2013.06.013 valvular abnormalities (tricuspid valve, no calcification) but did demonstrate the presence of a subvalvular proximal isovelocity surface area (Figure $1, B$ ) of $0.45 \mathrm{~cm}^{2}$ and reveal a subvalvular fixed obstruction (Figure 1,C) of area $0.8 \mathrm{~cm}^{2}$ and mean gradient $48 \mathrm{~mm} \mathrm{Hg}$, associated with left ventricular hypertrophy and moderate aortic regurgitation. A cardiac computed tomographic scan (Figure 1, A) confirmed the presence of a circumferential aortic subvalvular membrane in the left ventricular outflow tract, located $14 \mathrm{~mm}$ away from the aortic ring. This membranous or fibromuscular ring below the aortic valve was $8 \mathrm{~mm}$, whereas the left ventricular outflow tract was $15 \mathrm{~mm}$. Surgical procedure showed, after removal of the native aortic valve, a thick membrane located $15 \mathrm{~mm}$ from the aortic annulus. The membrane (Figure 1,D) was removed, and the aortic valve was replaced with a mechanical prosthesis. Echocardiographic control showed no more stenosis, and the patients symptoms resolved.

Subaortic stenosis is a manifestation of a geometric anatomic alteration in the left ventricular outflow tract. It seems
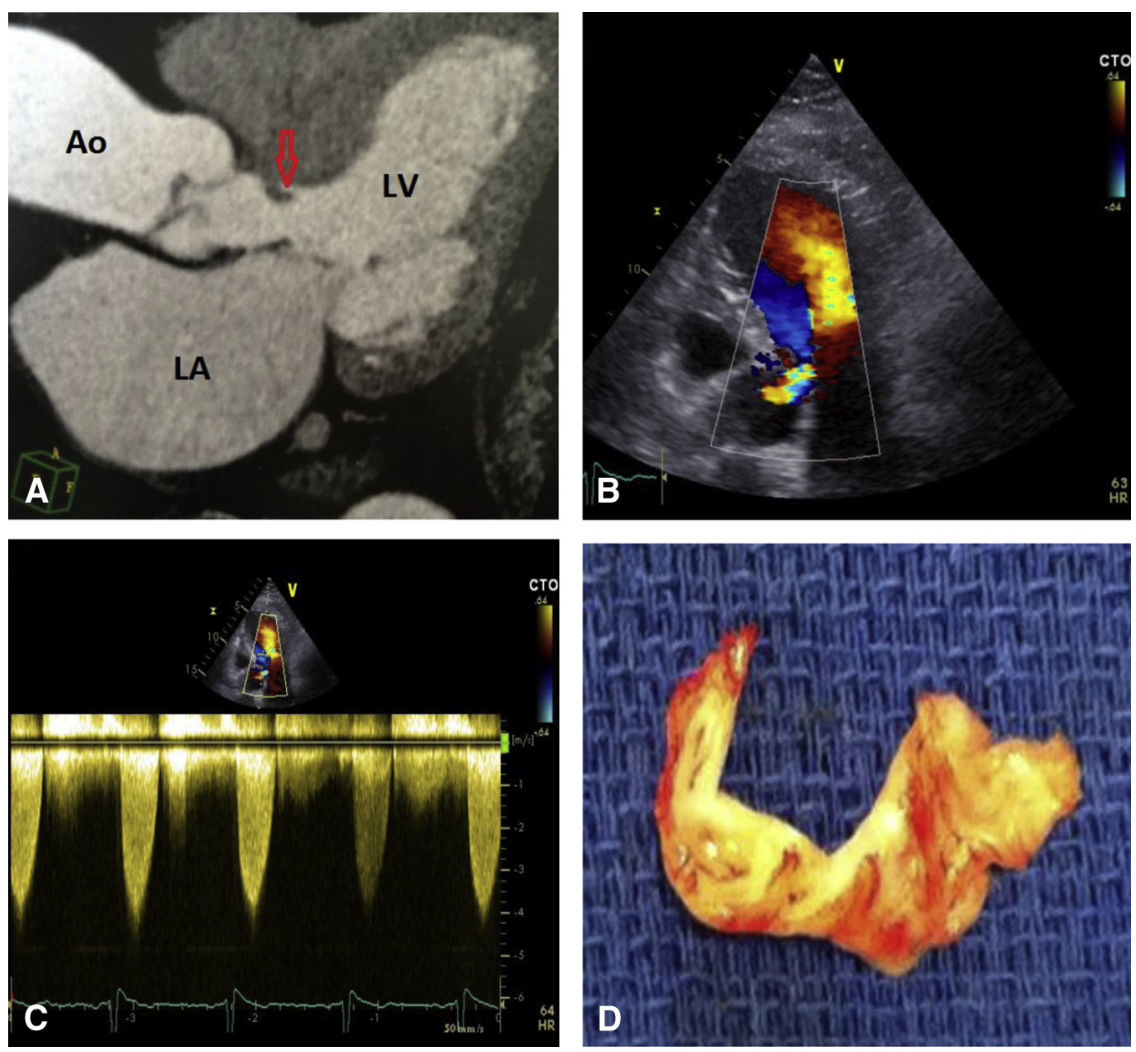

FIGURE 1. A, Heart computed tomographic scan showing the circumferential subvalvular membrane along the interventricular septum and mitral valve. $\mathrm{B}$, Echocardiography showing subvalvular proximal isovelocity surface area, $0.45 \mathrm{~cm}^{2}$. C, Aortic Doppler echocardiography showing severe fixed stenosis with maximum jet velocity $4 \mathrm{~m} / \mathrm{s}$. D, Image of the thick membrane after surgery. Ao, Aorta; $L V$, left ventricle; $L A$, left atrium. 
to be acquired, because it is almost never present at birth. It is sometimes associated with various other cardiac malformations, such as interventricular communication, double-inlet right ventricle, and aortic coarctation, that must be monitored and treated surgically when necessary. Apart from congenital cardiac abnormalities, acquired aortic insufficiency is the most common lesion found in association with subaortic stenosis. 